\title{
Health Care Workers' Risk Perceptions and Willingness to Report for Work during an Influenza Pandemic
}

\author{
Georges Dionne ${ }^{1, *}$, Denise Desjardins ${ }^{1}$, Martin Lebeau ${ }^{1}$, Stéphane Messier ${ }^{1}$ and \\ André Dascal ${ }^{2}$ \\ 1 Canada Research Chair in Risk Management, HEC Montréal, 3000 Cote Ste Catherine, Montreal, \\ QC H3T 2A7, Canada; denise.desjardins@cirrelt.ca (D.D.); martin.lebeau@hec.ca (M.L.); \\ stephane.messier@atuq.com (S.M.) \\ 2 Division of Infectious Diseases, Department of Medicine, Jewish General Hospital and McGill University, \\ Montréal, QC H3T 1E2, Canada; andre.dascal@mcgill.ca \\ * Correspondence: georges.dionne@hec.ca; Tel.: +1-514-340-6596; Fax: +1-514-340-5019
}

Received: 13 December 2017; Accepted: 31 January 2018; Published: 8 February 2018

\begin{abstract}
The ability and willingness of health care workers to report for work during a pandemic are essential to pandemic response. The main contribution of this article is to examine the relationship between risk perception of personal and work activities and willingness to report for work during an influenza pandemic. Data were collected through a quantitative Web-based survey sent to health care workers on the island of Montreal. Respondents were asked about their perception of various risks to obtain index measures of risk perception. A multinomial logit model was applied for the probability estimations, and a factor analysis was conducted to compute risk perception indexes (scores). Risk perception associated with personal and work activities is a significant predictor of intended presence at work during an influenza pandemic. This means that correcting perceptual biases should be a public policy concern. These results have not been previously reported in the literature. Many organizational variables are also significant.
\end{abstract}

Keywords: influenza pandemic; pandemic preparedness; risk perception; reporting for work; health policy; personal and work activities; principal component analysis

JEL Classification: D80; I11; I18

\section{Introduction}

Empirical evidence suggests that risk perception affects risk behavior. Those who underestimate the risk of lung cancer smoke more (Viscusi 1990, 1992), and those who underestimate the risk of being arrested due to impaired driving violate the Highway Safety Code more often and have more road accidents (Dionne et al. 2007). These results concern the direct link between risk-taking behavior and perception of that risk. They do not consider the link between a more general index of risk perception and risk behavior. This relationship is important for anticipating the behavior of individuals regarding a new risk for which information on past experience is lacking, such as a new influenza pandemic.

Major infectious disease outbreaks are a threat to public health. One important concern is whether health care workers (HCWs) will report for work (RFW) during such outbreaks. Perception of the risks associated with various activities may partly explain whether HCWs report for work during a pandemic. If risk perception is a significant factor, correcting perceptual biases may become a public policy concern (Leppin and Aro 2009). Previous studies have documented a relationship between risk perception of an influenza pandemic (IP) and HCWs' RFW (Leppin and Aro 2009). However, these 
risk perceptions of IP are often vague and not well documented, because the event never happened. In contrast, this article examines the influence of risk perception related to various personal and work activities on RFW during an influenza pandemic.

Our objectives are to: (i) document how a general index of risk perception related to personal and work activities (e.g., smoking and lung cancer, alcohol consumption and car accidents, influenza vaccination side effects, blood-tainted needle and HIV) would affect HCWs' RFW during an influenza pandemic; (ii) determine the conditional probability of HCWs' reporting for work during a pandemic wave; (iii) identify other factors that influence RFW (e.g., risk behavior in different activities, safety measures at work, pandemic preparedness, responsibility for dependents, personal life characteristics, access to transportation); and (iv) ascertain the extent to which the initial expressed intent of not RFW is reversible, and under which circumstances.

The remainder of the paper is organized as follows. Section 2 presents a review of the literature on risk perception and behavior. Section 3 specifies the models used to estimate the probability of being present at work. This section also describes the survey procedure used to obtain HCWs' views about their risk perception, behavior and intention to go to work during an influenza pandemic. Section 4 reports the results, and Section 5 concludes the analysis.

\section{Literature Review}

\subsection{Subjective Perception of Risk}

Over the past thirty-five years, many studies in psychology and economics have investigated the perception of risks and learning processes (i.e., revision of perceptions based on new information), together with their relation to decision-making. Combs and Slovic (1979) and Slovic et al. (1982) show that over-evaluated risks tend to be those that have been largely publicized. Information received from various sources plays a big role in risk perception, particularly for risks about which individuals have little information from their own experience. Several studies have examined the process by which new information modifies the perceptions of risk. Particular attention has been paid to specific actions (information campaigns, labeling, etc.). For example, Smith and Johnson (1988) have analyzed information campaigns on the dangers of exposure to radon and their effects on the perception of the risk of lung cancer caused by this gas. The findings confirm the effectiveness of communication policies in modifying risk perception (see also Smith et al. 1990; Magat et al. 1987).

These studies also conclude that communication measures have to be credible and compatible with the direct information that individuals could obtain from their own experience. The works of Arrow (1982), Viscusi and O'Connor (1984), Viscusi (1985), and Hakes and Viscusi (1997) suggest that learning processes are almost Bayesian; individuals assimilate most of the information that comes their way in a fairly coherent manner.

The rationality with which individuals handle information can be reconciled with the existence of perceptual biases. Perceived risks would be identical to objective risks if the individuals were perfectly informed. In a situation where individuals are poorly informed, however, their a priori perceptions will be very diffuse regarding different risks. High risks are often underestimated, and low risks overestimated. The acquisition of new knowledge may correct these perceptions. Thus, revised perceptions gain in objectivity depending on the quantity and quality of the new information acquired. Low risks may still be overestimated and high risks underestimated, but perceptual biases tend to be partially corrected.

\subsection{Risk Perception and Behavior}

Magat et al. (1987) studied the behaviors that risk perception generates. Information on the risks of using potentially dangerous domestic products is shown to lead consumers to make what can be called rational adjustments. Information indicating a high risk induces precautions in the use and storage of these kinds of products. 
The most widely studied case of the relation between risk perception and behavior concerns the decision to smoke. Viscusi $(1990,1992)$ investigated the link between smoking and the risk of developing lung cancer. The question initially raised is whether smokers in the United States underestimate the risk of developing cancer. The study's conclusions are congruent with the hypothesis positing a relation between behavior and risk perception, and with the result that the risks of unlikely but highly publicized events tend to be overestimated. All the respondents overestimated the risk of developing lung cancer from cigarettes. However, there is a significant difference between the perceptions of smokers and non-smokers: Smokers' perception of this risk is, on average, lower than that of non-smokers, which partly explains why they smoke.

Liu and Hsieh (1995) and Lundborg (2007) reproduce the main aspects of Viscusi's approach in their Taiwan study. Their findings are analogous. In the case of Spain, Antoñanzas et al. (2000a, 2000b) also find that non-smokers have stronger perceptions of the risks associated with cigarettes than do smokers. They show that young people overestimate these risks more than the average population and that more highly educated respondents overestimate risks less than the average individual. The latter finding may be explained by the fact that the risks perceived by the well-educated are better documented.

There are comparable studies on the relation between perceived risks and risk-taking in road safety. The studies rely on self-reported behavior (e.g., Anderson and Lundborg 2007; Brown and Cotton 2003; Ryb et al. 2006) or intentions regarding precautionary actions while driving (e.g., Parker et al. 1992; Phelps 1987; Stasson and Fishbein 1990; Svenson et al. 1985). Although these studies affirm a negative relationship between perceived risks and risk-taking, self-reported driving behavior (e.g., with respect to drinking and driving or to speeding) or intentions (e.g., the intention to commit violations or to wear a seatbelt) are probably subject to some bias. In a more recent article (Dionne et al. 2007), by contrast, actual behavior is inferred from objective data such as the individual's traffic violation record or involvement in accidents. The authors conclude that individuals who underestimate the probability of being arrested for impaired driving violate the Highway Safety Code more often and have more accidents. Results also indicate that those who overestimate also tend to commit more violations, although the effect is less pronounced and less frequent. One interpretation is that those with accurate risk perception commit fewer violations. Thus, as expected, underestimation of risk seems to lead to less prudent driving, but misperception (whether over- or underestimation) also seems to be associated with less prudent driving.

Carman and Kooreman (2014) find that perceived probabilities affect the take-up of risk reducing interventions for the prevention of heart disease even after controlling for individual predicted risk from epidemiological models. This is in line with the results from a meta-analysis (Brewer et al. 2007) suggesting that risk perception is a core concept in the theory of health behavior.

Very few studies have analyzed risk perception at work. Leoni (2010) demonstrates that risk perception is a function of objective risk factors such as hazardous working conditions and the probability of contracting an occupational illness. Personal characteristics and household structure also affect risk perception. The author does not study the effect of risk perception on risk-taking behavior.

Previous studies have documented the relationship between risk perception of an influenza pandemic and reporting for work (Ives et al. 2009). Our study does not consider the same risk perception. Rather, it analyzes the determinants of the perception of personal and work activity risks, along with the relationship between the perception of these risks and the behavior of reporting for work during an influenza pandemic. The choice of the "perception" factor is fundamental in that it may condition the social and economic impact of not reporting for work.

The main hypothesis of our research design is that to measure the effect of risk perception on intention to report for work in a pandemic, perceptions of risks associated with personal and work activities are more accurate than the perception of a previously unseen pandemic risk because HCWs regularly face personal and work activity risks and manage these risks according to their risk 
perceptions. In contrast, unseen pandemic risks are vaguer and often unknown for them. To our knowledge, this hypothesis has not been tested in the literature.

\subsection{Other Dimensions of Risk}

Risk is a concept that has many facets differing between individuals and between disciplines (Althaus 2005; Aven 2012a, 2012b; Aven and Kristensen 2005). Its perception can be objective, subjective, and even affective (Slovic et al. 1982). The definition of risk perception also differs across disciplines. Moreover, risk perception can be affected by previous experiences, including personal accidents. For example, we can use a Bayesian approach to show how individuals update risk perception in response to different past experiences when controlling for cognitive and socioeconomic factors.

In this research, the risk perceived by the respondents has two dimensions: the likelihood of the influenza pandemic event and its consequences on the respondents' health when they report for work. Subjects do not have to use probabilities to calculate the likelihood of the event, and their perception of the conditional severity of the consequences of reporting for work is personal and subjective. Our methodology tests how perception of both dimensions of risk is associated with past personal and work activities, and how risk perception is a significant predictor of intended presence at work during an influenza pandemic.

O’Neil et al. (2016) distinguish between perceived risk exposure and perceived risk by adding the geographical factor when considering flood-risk perception. In their study, distance to a flood risk exposure is a significant determinant of flood-risk perception. We do not think that such a geographical factor should affect risk perception in our study, because the questions we consider in order to estimate risk perception are related to events that are not dependent on the distance from a hazard. Nonetheless, the effect of risk perception on the decision to be present at work during an influenza pandemic is a function of distance. This explains why we control for access to transportation in the statistical analysis that links risk perception factors to the probability of being present at work. We must also emphasize that our analysis is purely statistical and does not use expert judgments to link risk perception and the decision to report for work during an influenza pandemic. It would be interesting, however, to compare the two approaches in a future study.

This research is also linked with the literature on the health-belief model (Abraham and Sheeran 2015), which predicts health-related behavior by taking into account individual differences in beliefs and attitudes. However, this literature often does not control for other factors that may influence health behavior. In our multivariate analysis of the decision to report for work, we control for many organizational factors that may influence the decision. As mentioned in the conclusion, our model does not isolate the emotional dimension of risk perception because we lack the information to do this type of analysis.

\section{Methods}

Table 1 describes the seven steps of the methodology that we describe below.

Table 1. Steps of the methodology. HCW: health care worker.

\begin{tabular}{lll}
\hline & SURVEY AND PROFESSION MISIDENTIFICATION \\
Step 1 & - & $\begin{array}{l}\text { 7 questions on risk perception, } 3 \text { questions on report for work during } \\
\text { influenza pandemic, and } 21 \text { questions on control variables. } \\
\text { Treatment of profession misidentification in the survey. }\end{array}$ \\
& - & TREATMENT OF MISSING DATA \\
Step 2 & - & $\begin{array}{l}\text { PROC MI (Multiple Imputation) in SAS version } 9.3 \text { to create } 100 \text { imputed } \\
\text { data sets of 3574 HCWs for } 21 \text { control variables from the survey. }\end{array}$ \\
\hline
\end{tabular}


Table 1. Cont.

\begin{tabular}{|c|c|c|}
\hline \multirow{5}{*}{ 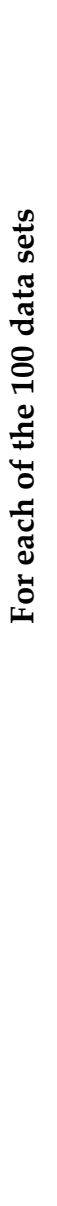 } & Step 3 & $\begin{array}{l}\text { - } \\
\text { - } \quad \text { Estimation of } 19 \text { predicted probabilities from } 7 \text { multinomial logit models * } \\
\text { One model for each risk perception question with } 4 \text { alternatives } \\
\text { (Overestimate, Underestimate, Unbiased, Unable to answer this question) } \\
\text { with } 10 \text { personal explanatory variables obtained from different questions in } \\
\text { the survey. One risk perception question had only } 3 \text { alternatives. }\end{array}$ \\
\hline & Step 4 & $\begin{array}{l}\text { PCA ** OR FACTOR ANALYSIS } \\
\text { - Three factor analyses to reduce the number of variables for the analysis of } \\
\text { willingness to report for work. } \\
\text { Obtain individual risk perception scores for overestimate, underestimate and } \\
\text { unbiased alternatives. One factor analysis by alternative. }\end{array}$ \\
\hline & Step 5 & $\begin{array}{l}\text { - INFLUENZA PANDEMIC SCENARIOS AND REPORTING FOR WORK } \\
\text { DURING AN INFLUENZA PANDEMIC } \\
\text { - } \quad \text { Influenza pandemic scenarios for dependent variables. } \\
\text { - } \quad \text { Pstimation of a multinomial logit model for presence at work * } \\
\text { percept, Not present, I don't know alternatives as a function of the risk } \\
\text { from the survey. }\end{array}$ \\
\hline & Step 6 & $\begin{array}{l}\text { - SUMMARY OF THE } 100 \text { MULTINOMIAL LOGIT ESTIMATES } \\
\text { PROC MIanalyze in SAS version } 9.3 \text { to generate valid statistical inferences by } \\
\text { combining the results from the } 100 \text { imputed data sets. }\end{array}$ \\
\hline & Step 7 & $\begin{array}{l}\text { - } \quad \text { ROBUSTNESS ANALYSIS } \\
\text { Additional analyses (Step } 3 \text { to Step 5) with } 3971 \mathrm{HCW} \text { observations and with } \\
\text { 3574 HCW observations using missing as a variable category instead of } \\
\text { imputing missing values. }\end{array}$ \\
\hline
\end{tabular}

\footnotetext{
${ }^{*}$ We used a normalized weight to adjust results based on population. It is stratified by profession and age. ${ }^{* *}$ PCA:
} Principal Component Analysis.

\subsection{Step 1: Survey and Profession Misidentification}

1. Survey. From 17 April 2008 to 29 January 2009, all HCWs in health professions practicing on the island of Montreal, as well as administrative and support staffs in 11 health care institutions in the same geographical area, were invited to participate in an anonymous, cross-sectional Web-based survey. The survey period ended before the first Novel Influenza A (H1N1) pandemic wave began. Sixteen health professions assisted by inviting their members to participate in the survey. To reach administrative and support staff workers, we enlisted the collaboration of 11 health care institutions with a total of 27,324 administrative and support workers with the following distribution: 4 hospitals (18,063 workers), 5 health and social services centers (6122 workers), and 2 youth and public rehabilitation centers (3139 workers). The survey was administered by an independent firm, SOM (Strategy Organization and Method). The questionnaire is available from the authors.

Table 2 details the number of HCWs on the island of Montreal and the number of respondents. Column A reports the population of healthcare workers on the island of Montreal. The information on the population comes from three sources: Statistics Canada for 15 health professions, the social workers association for their members working in the health care sector, and the eleven healthcare institutions that collaborated with the survey. A total of 3971 workers participated in the survey for an overall response rate of $3.79 \%$, varying from $2.60 \%$ to $8.15 \%$ depending on the profession. Our target was about 3950 responses due to budget constraints. Columns C and D present the mean age of each profession for the population and the respondents, respectively. Because the response rates vary 
among professions and age groups, we take these differences into account by using a normalized weight in the estimation of the probabilities to obtain results on the population base and eliminate potential bias. The estimation results thus represent the non-respondents, because they are adjusted to the population base.

2. Profession misidentification. HCWs from the mailing lists of the eleven institutions participating in the survey were targeted as Support Staff and Administrators. Many of the respondents (372) either identified themselves as a member of a health profession or did not answer the survey question that asked for their main profession or activity. Other workers (16) either identified themselves as members of a profession other than the ones used in the mailing lists, or did not indicate a profession (9). We do not consider these 397 workers as members of any profession in the first analyses done with 3574 observations, but we evaluate the effect of this choice in a robustness or sensitivity analysis with the 3971 workers of the sample.

Table 2. Health care workers on the Island of Montreal and survey participation.

\begin{tabular}{|c|c|c|c|c|c|}
\hline Profession & $\begin{array}{c}\text { Number of } \\
\text { Workers * A (\%) }\end{array}$ & $\begin{array}{c}\text { Number of } \\
\text { Respondents B (\%) }\end{array}$ & $\begin{array}{c}\text { Response Rate } \\
\text { (\%) B/A }\end{array}$ & $\begin{array}{l}\text { Mean Age } \\
\text { Population C }\end{array}$ & $\begin{array}{l}\text { Mean Age } \\
\text { Sample D }\end{array}$ \\
\hline Physician & $10,660(11.3)$ & $502(12.6)$ & 4.71 & 46.3 & 45.5 \\
\hline Nurse & $28,725(30.4)$ & $862(21.7)$ & 3.00 & 42.6 & 42.2 \\
\hline Nursing assistant & $4760(5.0)$ & $273(6.9)$ & 5.74 & 43.0 & 44.1 \\
\hline Dentist & $2590(2.7)$ & $90(2.3)$ & 3.47 & 44.3 & 48.5 \\
\hline Occupational therapist & $1655(1.8)$ & $77(1.9)$ & 4.65 & 36.7 & 35.5 \\
\hline Registered respiratory therapist & $1345(1.4)$ & $95(2.4)$ & 7.06 & 36.7 & 42.3 \\
\hline Pharmacist & $2725(2.9)$ & $169(4.3)$ & 6.20 & 42.3 & 40.3 \\
\hline Physiotherapist & $2310(2.4)$ & $74(1.9)$ & 3.20 & 37.9 & 39.1 \\
\hline Psychologist & $3920(4.1)$ & $102(2.6)$ & 2.60 & 45.9 & 45.9 \\
\hline Registered technologist & $1980(2.1)$ & $137(3.5)$ & 6.92 & 40.4 & 39.8 \\
\hline Radiology technologist & $2055(2.2)$ & $118(3.0)$ & 5.74 & 39.5 & 41.7 \\
\hline Social worker in health care ${ }^{* *}$ & $2210(2.3)$ & $156(3.9)$ & 7.06 & 41.9 & 43.5 \\
\hline Support staff *** & $26,149(27.7)$ & $1063(26.8)$ & 4.07 & 40.8 & 43.4 \\
\hline Administrator $* * *$ & $1175(1.2)$ & $181(4.6)$ & 15.40 & 47.7 & 49.6 \\
\hline Others $* * * *$ & $2211(2.3)$ & $72(1.8)$ & 3.26 & 40.4 & 41.5 \\
\hline Total & $94,470(100.0)$ & $3971(100.0)$ & 4.20 & 42.3 & 43.1 \\
\hline
\end{tabular}

* Number comes from Statistics Canada (2007) unless otherwise specified. ${ }^{* *}$ Number comes from social workers association because Statistics Canada does not separate social workers in health care from other social workers. *** Number comes from eleven health institutions in Montreal. ${ }^{* * *}$ Other categories include Chemist (3 respondents), Dietitian (35 resp.), Speech Therapist and Audiologist (30 resp.), and Midwife (4 resp.). Numbers come from Statistics Canada.

\subsection{Step 2: Treatment of Missing Data}

We had to deal with potential bias of non-responses to some of the questions. To eliminate potential bias due to non-responses to some questions, we used the multiple imputation (MI) method (Rubin 1987). We did 100 imputations to obtain 100 complete data sets and performed our analyses on each data set. The parameter estimates of the 100 separate analyses were then combined into a single value by applying PROC MIanalyze in SAS version 9.3 (SAS Institute Inc., version 9.3, Cary, NC, USA, 2011). We used the total variance associated with the parameter estimates, which is a combination of between-imputation variance and within-imputation variance, to compute the confidence intervals of the odd ratios. As a sensitivity analysis, the results of imputed analysis were compared with those of another analysis with a missing variable category.

\subsection{Step 3: Risk Perception}

We asked seven questions on risk perception of an influenza pandemic and on personal and work activities (see Table 3). To obtain the corresponding perceptual biases, HCWs were asked questions allowing comparisons between their responses and certain benchmarks (Viscusi 1992). The corresponding benchmarks were chosen prior to the survey based on previously published data and the team members' experience. For each question, we defined perception of risks as overestimated, underestimated, unbiased (benchmark), and unable to answer this question. 
Given the choice of two methodologies to measure bias in risk perception-using either risk perceptions stated by individuals (response to questions in the survey) or the predicted probabilities of overestimated, underestimated, and unbiased risk perception-we opted for the predicted conditional probability approach. By estimating the predicted probabilities, we solve the potential endogeneity problem associated with risk perception (Dionne et al. 2007). Some individuals may deny the dangers associated with certain habits in order to be able to raise their comfort level and thus continue them. For example, smokers may convince themselves that smoking is not dangerous for their health, and drinkers may convince themselves that drinking and driving is not dangerous. The four categories (overestimated, underestimated, unbiased, unable to answer this question) of the seven questions were treated qualitatively. They represent the dependent variables of the multinomial logit model. Seven multinomial logit models were estimated; one for each question in Table 3 and 100 times each. For each dependent risk perception question (e.g., lung cancer), we used the corresponding behavior or knowledge of HCWs (e.g., smoking, see Table 3) as an explanatory variable in the model. Workers not exposed to a given risk (see, for example, question 18 in Table 3 and the corresponding behavior) could answer "Does not apply to my situation". These answers were considered as a category in the multinomial logit analysis.

Table 3. Questions on risk perception and corresponding knowledge or behavior. MTL: Montreal; HIV: human immunodeficiency virus.

RISK PERCEPTION OF INFLUENZA PANDEMIC

- Question 6: INFLUENZA PANDEMic CASES-MTL

Now assuming that Montreal were to be affected by an influenza pandemic ... . Out of every 1000 Montrealers, how many do you predict would be infected during the total duration of the pandemic?

Knowledge question: Since 2003, how many cases of bird flu (H5N1) have been reported in humans worldwide?

- Question 7: INFLUENZA PANDEMic DEATHS-MTL

Out of every 1000 Montrealers infected with pandemic influenza, how many do you predict will die of the disease? Knowledge question: Among these cases (bird flu-H5N1—reported since 2003), what percent died from the illness? RISK PERCEPTION OF WORK ACTIVITIES

- Question 18: NeEdle STICK-HIV acQUisition

For every 10,000 health care workers who are accidentally pricked by a needle tainted by blood of an HIV infected patient, how many are at risk of contracting HIV in the absence of prevention?

Behavior question: Do you follow the recommended procedures for disposal of sharps to avoid accidently being pricked by a needle tainted with a patient's blood?

- Question 20: Viral ENTERITis-HCWs AfFeCted

Of all the cases of viral gastro-enteritis in health establishments in Montreal from September 2006 to May 2007, what percentage were health care workers?

Behavior question: If you work in a health establishment where there are cases of viral gastro-enteritis, do you wash your hands as recommended?

RISK PERCEPTION OF PERSONAL ACTIVITIES

- Question 11: Flu VAcCine-Mild Side EFFects

Among the 10 million Canadians vaccinated against seasonal influenza, how many do you think will suffer mild side effects?

Behavior question: During the past 12 months, did you receive the flu vaccine (seasonal influenza)?

- Question 16: SMOKING- Lung CANCER

By how much does a man who smokes regularly increase his chances of dying of lung cancer, compared to a non-smoker? Behavior question: Do you currently smoke cigarettes?

- QUESTION 22: DRINKING \& DRIVING-CAR ACCIDENTS

It is suspected that on any given Friday night, there are about 20,000 drivers in Quebec who drive with impaired faculties. In your opinion, how many of them will have an accident, regardless of whether they are responsible for the accident and regardless of the severity of the crash?

Behavior question: During the past 3 months, how many times did you drive a car after having had 2 or more drinks during the preceding hour? 
In addition, nine personal variables originating from the survey are included in the model as control variables: number of children under 14, responsibility for people with limited autonomy, workplace, profession, full-time work, personal health, years of experience in the health sector, main task as a worker in the health sector, and whether their work put them in frequent and regular contact with patients. These personal variables are introduced in the model to minimize the potential endogeneity problem discussed above and to predict the individuals' risk probabilities. They differ from the organizational variables of the presence at work model (to be presented later) to reduce a potential multi-collinearity problem in estimating the probability of being present at work during an influenza pandemic because the predicted probabilities of risk perception that generate the risk perception scores are function of personal characteristics. As mentioned in the introduction, our analysis has two parts: first we analyze individual risk perception as a function of personal characteristics and then we relate reporting for work intention to estimated individual risk perception and organizational factors.

\subsection{Step 4: Principal Component Analysis (PCA) or Factor Analysis}

We used factor analysis (Kim and Mueller 1978) to compute risk perception scores (or indexes), which are a combination of the predicted probability estimates of three types of risk perception: risk perception of influenza pandemic, risk perception of work activities, and risk perception of personal activities. We performed three factor analyses, one for each risk perception: underestimated risk, overestimated risk, or unbiased risk perception. Our goal was to reduce the number of predicted probabilities (19) estimated by the seven multinomial logit models described above (seven predicted probabilities of overestimated risk, five predicted probabilities of underestimated risk, and seven predicted probabilities of unbiased risk perception), into a smaller set of variables called principal component factors that account for most of the variance of the predicted probabilities. This approach is based on an analysis of the covariance matrix of the underlying risk perceptions, which captures the correlation among predicted probabilities. We applied the Kaiser criterion (Kim and Mueller 1978) to retain and interpret the principal components that account for a meaningful amount of variance. We used the principal component method to estimate the values of the loadings, which are equivalent to correlations between predicted probabilities and components. We considered a loading salient or sufficiently large when its absolute value exceeds 0.40 . Finally, we used the regression-based factor scores method (Proc score in Statistical Analysis Software (SAS)) to estimate individuals' risk perception scores (RPS) for measuring the effect of risk perception in the analysis of reporting for work during an influenza pandemic.

\subsection{Step 5: Influenza Pandemic Scenarios and Reporting for Work during an Influenza Pandemic}

1. Influenza pandemic scenarios for dependent variables. Three influenza pandemic (IP) scenarios affect reporting for work (RFW) during an influenza pandemic. They correspond to three simulated weeks of a potential IP wave in Montreal (MTL) four weeks after a pandemic declaration by the WHO. For each scenario, the number of hospitalizations and deaths was derived using FluSurge 2.0 (attack rate of $15 \%$ and mortality rate of $0.23 \%$, https:/ / www.cdc.gov/flu/pandemic-resources/tools/flusurge.htm). The information from the three scenarios is summarized in Panel A of Table 4. The same wording was used for the presentation of the three scenarios; only the numbers were changed. The third scenario was presented to the HCWs as follows: "Six weeks since the first cases were reported in Montreal, a total of 85,770 cases of pandemic influenza have been confirmed among Montreal residents, including 1206 hospitalizations and 160 deaths. 4289 cases of pandemic influenza among health care workers have been confirmed on the island of Montreal, 60 have been hospitalized, and 8 have died. Under such a scenario, would you show up for work?" The possible answers to each scenario were "Yes", "No," and "I don't know". This third scenario was more serious than the A (H1N1) influenza pandemic. The following analysis is based on the answers to this scenario. 
2. Reporting for work during an influenza pandemic. We estimated a multinomial logit model (100 times to reduce potential bias) to test how the risk perception scores can affect HCWs' reporting for work (RFW). The three alternatives for the dependent variables are: Yes, No, I don't know. The main hypothesis is that risk perception scores of personal and work activities will have greater power to explain the probability of being present at work than the risk perception scores of an influenza pandemic. Organizational variables included in the model include hygiene safety measures put in place by the establishment, preparation to protect workers in the event of a pandemic, their role at work in the event of a pandemic, importance of their role at work during an influenza pandemic, avoiding car-pooling or public transportation, and access to methods of transportation other than car-pooling or public transportation. The model also includes the following variable: changed behavior out of fear of contracting an infectious disease. The latter behavior variable contains information on risk perception. It is treated differently from the other risk perception variables on personal and work activities because we do not have information on the individual's risk perception of the corresponding infectious disease.

Table 4. Presence at work during an influenza pandemic.

\begin{tabular}{|c|c|c|c|c|c|c|c|c|}
\hline \multicolumn{9}{|c|}{$\begin{array}{l}\text { Panel A } \\
\text { Three fictitious scenarios of the IP wave in Montreal (MTL) }\end{array}$} \\
\hline & & \multicolumn{3}{|c|}{ Scenario 1} & \multicolumn{2}{|c|}{ Scenario 2} & \multicolumn{2}{|r|}{ Scenario 3} \\
\hline \multicolumn{2}{|c|}{ Time in Montreal (MTL) } & \multicolumn{3}{|c|}{1 Week } & \multicolumn{2}{|c|}{2 Weeks } & \multicolumn{2}{|r|}{6 Weeks } \\
\hline \multicolumn{2}{|c|}{ Total ill in MTL } & \multicolumn{3}{|c|}{13} & \multicolumn{2}{|c|}{14,915} & \multicolumn{2}{|r|}{85,770} \\
\hline \multicolumn{2}{|c|}{ Total hospitalized in MTL } & \multicolumn{3}{|c|}{1} & \multicolumn{2}{|c|}{148} & \multicolumn{2}{|r|}{$\begin{array}{c}85,1 / 0 \\
1206\end{array}$} \\
\hline Total deaths in MTI & & \multicolumn{3}{|c|}{0} & \multicolumn{2}{|c|}{4} & \multicolumn{2}{|r|}{$\begin{array}{l}1200 \\
160\end{array}$} \\
\hline Total HCWs ill in M7 & & \multicolumn{3}{|c|}{1} & \multicolumn{2}{|c|}{746} & \multicolumn{2}{|r|}{4289} \\
\hline Total HCWs hospitalized & MTL & \multicolumn{3}{|c|}{0} & \multicolumn{2}{|c|}{7} & \multicolumn{2}{|r|}{60} \\
\hline Total HCWs deaths in 1 & & \multicolumn{3}{|c|}{0} & \multicolumn{2}{|c|}{0} & \multicolumn{2}{|r|}{8} \\
\hline \multicolumn{9}{|l|}{$\begin{array}{l}\text { Panel B } \\
\text { Health care }\end{array}$} \\
\hline & & \multicolumn{2}{|c|}{ Scenario 1} & \multicolumn{3}{|c|}{ Scenario 2} & \multicolumn{2}{|c|}{ Scenario 3} \\
\hline & & $\mathbf{N}$ & $\%$ & $\mathbf{N}$ & & & $\mathbf{N}$ & $\%$ \\
\hline Yes & & 3159 & 88.39 & 2614 & & & 1652 & 52.06 \\
\hline No & & 152 & 4.25 & 249 & & & 580 & 18.28 \\
\hline I don't know & & 263 & 7.36 & 559 & & & 941 & 29.66 \\
\hline Total & & 3574 & 100.0 & 3422 & & & 3173 & 100.00 \\
\hline \multicolumn{9}{|l|}{$\begin{array}{l}\text { Panel C } \\
\text { If there wo }\end{array}$} \\
\hline & & & Not & ent in & & & Do Not & now if Would \\
\hline & & $\operatorname{ario} 1$ & & o 2 & & & Be Prese & $t$ in Scenario 3 \\
\hline Yes & 60 & 39.47 & 98 & 39.36 & 259 & 44.66 & 538 & 57.17 \\
\hline No & 85 & 55.92 & 128 & 51.40 & 255 & 43.97 & 222 & 23.59 \\
\hline I don't know & 7 & 4.61 & 23 & 9.24 & 66 & 11.38 & 181 & 19.24 \\
\hline Total & 152 & 100.00 & 249 & 100.00 & 580 & 100.01 & 941 & 100.00 \\
\hline
\end{tabular}

\subsection{Steps 6 and 7: Summary of the 100 Multinomial Logit Estimates and Robustness Analysis}

Estimations of the 100 multinomial logit models were done with Proc Logistic in SAS version 9.3. The same software generates valid statistical inferences by combining the estimation results from the 100 imputed data sets. Finally, for sensitivity, two additional analyses were conducted with the 3971 HCW observations and with $3574 \mathrm{HCW}$ observations using "missing" as a variable category instead of imputing missing values. 


\section{Results}

\subsection{Sample}

3971 health care workers participated in the Web survey. 397 respondents were excluded from the analysis because of profession misidentification. The analysis was therefore conducted on 3574 respondents. A robustness analysis was also performed on all 3971 respondents.

\subsection{Presence at Work in the Three Scenarios}

Panel B of Table 4 describes the HCWs' intention to be present at or absent from work in each scenario of the survey. As the IP wave evolved, RFW decreases from $88 \%$ in Scenario 1 to $52 \%$ in Scenario 3, a result that is consistent with the literature (Balicer et al. 2006). Subjects who answered "No" to a given scenario were not questioned further on their intentions to report for work. The indecision rate increases with the severity of the scenarios. 30\% did not know whether they would go to work or not in the more severe (advanced) scenario.

For the statistical analysis, we retained the following response profile of presence at work during an influenza pandemic for the 3574 respondents: "Not present in at least one scenario" and "Present in the third scenario". We assumed that those who said "No" in the two previous scenarios would not change their mind if there were no shortage of health care workers. After the modification of the negative answers, $27.4 \%$ (981) of the 3574 subjects answered "Not present in at least one scenario", $26.3 \%(941 / 3574)$ did not know what they would do in the third scenario, and 46.2\% $(1652 / 3574)$ responded "Yes" in the third scenario.

We also considered the extent to which a possible shortage of health care workers could reverse a negative answer for each scenario and for the response "I don't know" in the third scenario. Panel C of Table 4 indicates that $45 \%$ of those who responded " $\mathrm{No}^{\prime}$ in the third scenario and $57 \%$ of those who answered "I don't know" in the third scenario would reverse their decision and report for work if there were an urgent shortage of health care workers during an IP.

\subsection{Estimation of Risk Perception}

The main significant personal variables (not reported here but available from the authors) that explain the individual risk perception probabilities are (1) for influenza pandemic risk perception: knowledge of $\mathrm{H} 5 \mathrm{~N} 1$ cases and \% H5N1 deaths, having children, workplace, profession, main task at work, full-time work, years of experience in health care, and personal health; (2) for work activity risk perception: having children, workplace, profession, main task at work, full-time work, years of experience in health care, and personal health; and (3) for personal activity risk perception: receiving the flu vaccine, smoking, drinking before driving, having children, workplace, profession, full-time work, years of experience in health care, and personal health. These variables were used to compute the 19 predicted probabilities of risk perception documented in Table 5.

\subsection{Barriers to Report for Work and Suggested Measures}

The four main barriers to willingness to report for work mentioned by the 981 HCWs who said "No" in the three scenarios documented in Panel B of Table 4 are: (1) I want to protect my personal health (50\%); (2) I want to protect my family's health $(36 \%)$; (3) I have to take care of my children or other dependents (5\%); and (4) I do not trust the safety measures at my work (4\%).

The three main measures, proposed by these HCWs, that the employer could put in place to minimize the impacts of an influenza pandemic are: (1) Reinforced workplace protection measures $(56 \%)$; (2) Giving more access to preventive medication (29\%); and (3) Better defining my role in such a scenario $(7 \%)$. 
Table 5. Principal component analyses (PCA) of risk perception and Varimax rotated component matrix *.

\begin{tabular}{|c|c|c|c|}
\hline \multirow{2}{*}{$\begin{array}{l}\text { STANDARDIZED PREDICTED PROBABILITIES OF RISK PERCEPTION } \\
\text { Factor analysis 1: PCA on Overestimate Risk }\end{array}$} & \multicolumn{2}{|c|}{$\begin{array}{c}\text { PRINCIPAL } \\
\text { COMPONENTS }\end{array}$} & \multirow[t]{2}{*}{ Communality } \\
\hline & PC 1.1 & PC 1.2 & \\
\hline Overestimated influenza pandemic cases & 0.06 & 0.89 & 0.79 \\
\hline Overestimated influenza pandemic deaths & 0.08 & $\overline{0.87}$ & 0.77 \\
\hline Overestimated mild side effects of flu vaccine & $\underline{0.69}$ & -0.09 & 0.48 \\
\hline Overestimated the risk of contracting HIV in absence of prevention & $\underline{\underline{0.83}}$ & -0.06 & 0.69 \\
\hline Overestimated cases of viral enteritis among HCWs & $\overline{0.43}$ & 0.10 & 0.20 \\
\hline Overestimated chances of a smoker of dying of lung cancer & $\underline{0.48}$ & 0.15 & 0.25 \\
\hline Overestimated number of accidents with impaired faculties & $\underline{\underline{0.71}}$ & 0.13 & 0.53 \\
\hline \multicolumn{4}{|l|}{$\%$ of the total variance explained: $53 \%$} \\
\hline Factor Analysis 2: PCA on Underestimate Risk & PC 2.1 & PC 2.2 & \\
\hline Underestimated mild side effects of flu vaccine & 0.16 & $\underline{0.62}$ & 0.41 \\
\hline Underestimated the risk of contracting HIV in absence of prevention & $\underline{0.86}$ & -0.14 & 0.77 \\
\hline Underestimated cases of viral enteritis among HCWs & $\underline{\underline{0.88}}$ & 0.10 & 0.78 \\
\hline Underestimated chances of a smoker of dying of lung cancer & $\overline{-0.05}$ & $\underline{0.64}$ & 0.41 \\
\hline Inverse of underestimated number of accidents with impaired faculties & -0.18 & $\overline{0.74}$ & 0.59 \\
\hline \multicolumn{4}{|l|}{$\%$ of the total variance explained: $59 \%$} \\
\hline Factor analysis 3: PCA on Unbiased Perception & PC 3.1 & PC 3.2 & \\
\hline Unbiased perception of influenza pandemic cases & 0.32 & $\underline{0.64}$ & 0.51 \\
\hline Unbiased perception of influenza pandemic deaths & -0.25 & $\underline{0.71}$ & 0.57 \\
\hline Unbiased perception of mild side effects of flu vaccine & $\underline{0.80}$ & 0.21 & 0.68 \\
\hline Unbiased perception of contracting HIV in absence of prevention & $\overline{0.81}$ & 0.25 & 0.72 \\
\hline Unbiased perception of cases of viral enteritis among HCWs & $\underline{0.74}$ & -0.13 & 0.56 \\
\hline Unbiased perception of the chances of a smoker of dying of lung cancer & $\overline{0.73}$ & 0.00 & 0.53 \\
\hline Unbiased perception of number of accidents with impaired faculties & $\overline{0.12}$ & $\underline{0.59}$ & 0.36 \\
\hline$\%$ of the total variance explained: $56 \%$ & & & \\
\hline
\end{tabular}

\subsection{Factor Analysis}

Our sample size has 3574 subjects, which is much larger than the number of predicted probabilities being analyzed. Indeed, the Kaiser-Meyer-Olkin measures of sampling adequacy are 0.61, 0.51 and 0.60 for the three factor analyses, indicating that we could reliably perform factor analyses on our data set.

The three factor analyses were run on the standardized predicted probabilities (mean $=0$, variance $=1$ ) listed in the first column of Table 5 using Proc Factor in SAS. The next two columns display the rotated component matrix for the predicted probabilities. The loadings in the matrix represent the correlations between the predicted probabilities and the factors of the principal components. The results identify two principal components with eigenvalues greater than 1 for each factor analysis. For the first case on predicted probabilities of overestimating risk, the two principal components underlined (PC 1.1, PC 1.2) explain 53\% of the total variance of the corresponding data. For the second factor analysis on predicted probabilities of underestimating risk, the two principal components (PC 2.1, PC 2.2) explain 59\% of the total variance. For the third analysis on predicted probabilities of unbiased risk perception, the two principal components (PC 3.1, PC 3.2) explain 56\% of the total variance. The communality values in the last column indicate that the two principal components of each factor analysis explain a large proportion ( $\geq 45 \%$ with few exceptions) of each of the predicted probabilities. We also observe from the matrix that each predicted probability is highly correlated $(\geq 0.40$, underlined) with one of the two components in each analysis. Finally, we observe that the data analysis did not separate personal and work activities for risk overestimation whereas it separated them for risk underestimation. 


\subsection{Risk Perception and Reporting for Work}

The results of the Multinomial Logit model used to estimate presence at work during a pandemic are presented in Table 6, which reports the multivariate Odds Ratios (ORs), 95\% CI (Confidence interval), and p-values of the variables that explain the probability of being present at work in the third scenario relative to that of not being present for at least one scenario. The first column of results presents the ORs obtained with imputed data for the missing data and a weight variable according to age and profession. The two other columns document robustness analyses. The second column considers the missing data as a category with the 3574 subjects, while the third column presents the same analysis of the missing data with the 3971 respondents. Because the results are about the same in all three columns, we concentrate the interpretation of the results in the first column. The results support our primary hypothesis. The risk perception score (RPS) of overestimating the risk of an influenza pandemic $\left(q_{6}, q_{7}\right)$ is not statistically significant, while the overestimated score of personal and work activities $\left(\mathrm{q}_{11}, \mathrm{q}_{18}, \mathrm{q}_{16}, \mathrm{q}_{20}, \mathrm{q}_{22}\right)$ is significant. Those who overestimate the risk of personal and work activities have a lower probability of being present at work $(\mathrm{OR}=0.72)$. We also observe that those who underestimate the risk of work activities $\left(\mathrm{q}_{18}, \mathrm{q}_{20}\right)$ and of personal activities $\left(\mathrm{q}_{11}, \mathrm{q}_{16}, \mathrm{q}_{22}\right)$ are more likely to be present at work $(\mathrm{OR}=1.21)$, even if they were separated by the factor analysis. It is also interesting to observe that the two unbiased risk perception variables do not affect the probability of being at work during an influenza pandemic (with one exception in column 3).

At the bottom of Table 6, we present the average predicted probabilities of being at work during an influenza pandemic for the three significant risk perception scores. The average predicted probability of being at work during an influenza pandemic is $46 \%$ (95\% CI: 46-46\%), which is the overall sample mean. It is equal to $36 \%(95 \%$ CI: 35-37\%) for those overestimating the risk of personal and work activities, $49 \%$ (95\% CI: 48-50\%) for those underestimating the risk of personal activities, and 53\% (95\% CI: 52-54\%) for those underestimating the risk of work activities.

Table 6 also documents interesting results for organizational variables not related to the risk perception scores. For instance, variables such as hygiene safety measures at work, role at work and the importance of this role in the event of a pandemic, and transportation to work during a pandemic are significant factors that explain presence at work. Similar results are documented in the literature. Finally, the variable change in behavior related to infectious disease also explains the presence at work (OR: 1.58 for those who did not). We now discuss the most organizational significant variables (multivariate OR, 95\% CI).

As the table shows, insufficient $(\mathrm{OR}=0.59)$ and highly insufficient $(\mathrm{OR}=0.38)$ hygiene safety at work and unimportant $(\mathrm{OR}=0.47)$ and not at all important $(\mathrm{OR}=0.46)$ role at work during an influenza pandemic reduce the probability of being present at work, while those who believe they have an essential $(\mathrm{OR}=1.95)$ or very important $(\mathrm{OR}=1.40)$ role at work during a pandemic have a higher probability of reporting for work. Other respondents with a higher probability of reporting for work are those who would not avoid car-pooling and public transportation $(\mathrm{OR}=3.11)$ in the event of a pandemic. Those who do not have access to methods other than car-pooling or public transportation would be less likely to be present at work during a pandemic $(\mathrm{OR}=0.62)$.

The robustness analyses, presented in the two next columns, indicate that there is no evidence of a poor model fit in our analysis due to the treatment of missing data and the non-response bias in the survey. 
Table 6. Odds ratio (95\% confident interval) on the probability of being present at work in the third scenario relative to that of not being present for at least one scenario $\left(\mathrm{q}_{i}\right.$ indicates the survey question $\left.i\right)$ *

\begin{tabular}{|c|c|c|c|c|c|c|}
\hline Variable & $\begin{array}{l}3574 \text { Impute Data \& Weight } \\
\text { Variables OR ( } 95 \% \text { CI) }\end{array}$ & $p$-Value & $\begin{array}{c}3574 \text { Missing as } \\
\text { Category OR ( } 95 \% \mathrm{CI})\end{array}$ & $p$-Value & $\begin{array}{c}3971 \text { Missing as } \\
\text { Category OR ( } 95 \% \mathrm{CI})\end{array}$ & $p$-Value \\
\hline \multicolumn{7}{|l|}{ Risk perception score (RPS) } \\
\hline RPS of overestimated risk of personal and work activities ( $q_{11} q_{18} q_{20} q_{16} q_{22}$ ) & $0.72(0.65-0.80)$ & $<0.001$ & $0.76(0.69-0.83)$ & $<0.001$ & $0.77(0.70-0.84)$ & $<0.001$ \\
\hline RPS of overestimated risk of influenza pandemic $\left(q_{6} q_{7}\right)$ & $1.03(0.94-1.13)$ & 0.525 & $1.04(0.94-1.14)$ & 0.496 & $1.03(0.94-1.13)$ & 0.541 \\
\hline RPS of underestimated risk of work activities $\left(\mathrm{q}_{18} \mathrm{q}_{20}\right)$ & $1.21(1.10-1.34)$ & $<0.001$ & $1.14(1.04-1.26)$ & 0.008 & $1.14(1.04-1.25)$ & 0.006 \\
\hline RPS of underestimated risk of personal activities $\left(\mathrm{q}_{11} \mathrm{q}_{16} \mathrm{q}_{22}\right)$ & $1.21(1.09-1.34)$ & $<0.001$ & $1.26(1.14-1.39)$ & $<0.001$ & $1.26(1.15-1.38)$ & $<0.001$ \\
\hline RSP of unbiased risk perception of personal and work activities $\left(q_{11} q_{18} q_{20} q_{16}\right)$ & $1.06(0.95-1.18)$ & 0.336 & $1.08(0.97-1.19)$ & 0.166 & $1.03(0.93-1.13)$ & 0.580 \\
\hline RPS of unbiased risk perception of influenza pandemic and personal activity ( $\mathrm{q}_{6} \mathrm{q}_{7} \mathrm{q}_{22}$ ) & $1.06(0.96-1.16)$ & 0.235 & $1.13(1.03-1.24)$ & 0.010 & $1.14(1.04-1.25)$ & 0.004 \\
\hline \multicolumn{7}{|l|}{ Hygiene safety measures $\left(\mathrm{q}_{5}\right)$} \\
\hline Highly sufficient & $0.82(0.59-1.13)$ & 0.222 & $0.84(0.61-1.17)$ & 0.301 & $0.83(0.61-1.12)$ & 0.223 \\
\hline Sufficient & 1 & & 1 & & 1 & \\
\hline Insufficient & $0.59(0.48-0.72)$ & $<0.001$ & $0.58(0.47-0.72)$ & $<0.001$ & $0.58(0.48-0.70)$ & $<0.001$ \\
\hline Highly insufficient & $0.38(0.26-0.56)$ & $<0.001$ & $0.40(0.27-0.59)$ & $<0.001$ & $0.44(0.30-0.63)$ & $<0.001$ \\
\hline Missing & 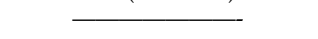 & - & $0.69(0.39-1.24)$ & 0.212 & $0.60(0.35-1.03)$ & 0.065 \\
\hline \multicolumn{7}{|l|}{ Preparation at workplace for a pandemic $\left(\mathrm{q}_{8}\right)$} \\
\hline Highly insufficient & $0.88(0.66-1.17)$ & 0.379 & $0.82(0.62-1.10)$ & 0.182 & $0.80(0.61-1.04)$ & 0.098 \\
\hline Insufficient & $1.00(0.80-1.25)$ & 0.983 & $1.01(0.81-1.26)$ & 0.960 & $0.98(0.80-1.21)$ & 0.872 \\
\hline Sufficient & 1 & & 1 & & 1 & \\
\hline Exaggerated & $0.79(0.32-1.99)$ & 0.621 & $0.90(0.37-2.20)$ & 0.819 & $0.98(0.41-2.31)$ & 0.959 \\
\hline Missing & & - & $1.58(1.12-2.21)$ & 0.009 & $1.46(.106-2.01$ & 0.021 \\
\hline \multicolumn{7}{|l|}{ Know your role at work in the event of pandemic $\left(\mathrm{q}_{9 \mathrm{a}}\right)$} \\
\hline Very well & $1.98(1.23-3.18)$ & 0.005 & $1.85(1.17-2.91)$ & 0.008 & $2.01(1.30-3.11)$ & 0.002 \\
\hline Well & $1.63(1.22-2.19)$ & 0.001 & $1.66(1.24-2.21)$ & $<0.001$ & $1.64(1.24-2.15)$ & $<0.001$ \\
\hline Not very well & $1.02(0.83-1.25)$ & 0.823 & $1.08(0.88-1.32)$ & 0.488 & $1.10(0.91-1.34)$ & 0.332 \\
\hline Not at all & 1 & & 1 & & 1 & \\
\hline Missing & - & - & $1.05(0.42-2.67)$ & 0.912 & $1.02(0.43-2.40)$ & 0.970 \\
\hline \multicolumn{7}{|l|}{ Your role at work during an influenza pandemic ( $\left.\mathrm{q}_{9}\right)$} \\
\hline Essential & $1.95(1.50-2.53)$ & $<0.001$ & $2.18(1.68-2.84)$ & $<0.001$ & $2.21(1.72-2.84)$ & $<0.001$ \\
\hline Very important & $1.40(1.12-1.77)$ & 0.004 & $1.56(1.24-1.96)$ & $<0.001$ & $1.56(1.25-1.93)$ & $<0.001$ \\
\hline Important & 1 & & 1 & & 1 & \\
\hline Of little importance & $0.47(0.36-0.61)$ & $<0.001$ & $0.47(0.36-0.62)$ & $<0.001$ & $0.46(0.35-0.59)$ & $<0.001$ \\
\hline Not at all important & $0.46(0.29-0.70)$ & $<0.001$ & $0.46(0.29-0.74)$ & 0.001 & $0.41(0.27-0.65)$ & $<0.001$ \\
\hline Missing & & - & $1.18(0.47-2.98)$ & 0.724 & $0.95(0.41-2.20)$ & 0.908 \\
\hline \multicolumn{7}{|l|}{ Changed your behavior at work for fear of contracting an infectious disease $\left(\mathrm{q}_{32}\right)$} \\
\hline Yes & 1 & & 1 & & 1 & \\
\hline No & $1.58(1.19-2.11)$ & 0.002 & $1.52(1.14-2.03)$ & 0.005 & $1.56(1.18-2.04)$ & 0.002 \\
\hline Missing & 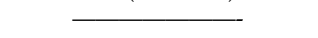 & - & $0.56(0.21-1.51)$ & 0.253 & $0.65(0.25-1.70)$ & 0.383 \\
\hline
\end{tabular}


Table 6. Cont.

\begin{tabular}{|c|c|c|c|c|c|c|}
\hline Variable & $\begin{array}{l}\text { 3574 Impute Data \& Weight } \\
\text { Variables OR }(95 \% \text { CI })\end{array}$ & $p$-Value & $\begin{array}{c}3574 \text { Missing as } \\
\text { Category OR ( } 95 \% \mathrm{CI})\end{array}$ & $p$-Value & $\begin{array}{c}3971 \text { Missing as } \\
\text { Category OR }(95 \% \mathrm{CI})\end{array}$ & $p$-Value \\
\hline \multicolumn{7}{|l|}{ Avoid car-pooling or public transportation during a pandemic $\left(\mathrm{q}_{33}\right)$} \\
\hline Yes & 1 & & 1 & & 1 & \\
\hline No & $3.11(2.45-3.95)$ & $<0.001$ & $3.59(2.80-4.60)$ & $<0.001$ & $3.60(2.84-4.57)$ & $<0.001$ \\
\hline Missing & - & - & $3.17(1.86-5.40)$ & $<0.001$ & $3.64(2.16-6.15)$ & $<0.001$ \\
\hline \multicolumn{7}{|l|}{ Other method of transportation than car-pooling or public transportation $\left(\mathrm{q}_{34}\right)$} \\
\hline Yes & 1 & & 1 & & 1 & \\
\hline No & $0.62(0.48-0.80)$ & $<0.001$ & $0.55(0.42-0.71)$ & $<0.001$ & $0.55(0.43-0.70)$ & $<0.001$ \\
\hline Missing & & - & $0.22(0.04-1.13)$ & 0.070 & $0.22(0.05-0.92)$ & 0.038 \\
\hline Risk perception score & $\begin{array}{c}\text { Average Predicted } \\
\text { Probabilities to Report for } \\
\text { Work }(95 \% \text { CI })\end{array}$ & $\mathrm{N}$ & $\begin{array}{c}\text { Average Predicted } \\
\text { Probabilities to Report } \\
\text { for Work }(95 \% \text { CI })\end{array}$ & $\mathrm{N}$ & $\begin{array}{c}\text { Average Predicted } \\
\text { Probabilities to Report } \\
\text { for Work }(95 \% \text { CI })\end{array}$ & $\mathrm{N}$ \\
\hline RPS of overestimate risk of personal and work activities $\left(q_{11} q_{18} q_{20} q_{16} q_{22}\right)$ & $0.36(0.35-0.37)$ & 723 & $0.38(0.36-0.39)$ & 725 & $0.38(0.37-0.39)$ & 782 \\
\hline RPS of underestimate risk of work activities $\left(q_{18} q_{20}\right)$ & $0.53(0.52-0.54)$ & 562 & $0.52(0.50-0.54)$ & 552 & $0.54(0.52-0.55)$ & 598 \\
\hline RPS of underestimate risk of personal activities $\left(q_{11} q_{16} q_{22}\right)$ & $0.49(0.48-0.50)$ & 640 & $0.50(0.48-0.51)$ & 663 & $0.51(0.49-0.52)$ & 754 \\
\hline Overall & $0.46(0.46-0.46)$ & 3574 & $0.46(0.45-0.47)$ & 3574 & $0.47(0.46-0.47)$ & 3971 \\
\hline
\end{tabular}

* The values of the risk perception scores (RPS) are the sum of the products of the standardized predicted probabilities and their respective standardized scoring coefficients, which are computed by multiplying the inverse of the predicted probabilities correlation matrix by the loadings in the matrix documented in the two PC columns of Table 5 . 


\section{Conclusions}

Planning of resource allocation during an influenza pandemic must be based on sound research that generates useful empirical results. Our results affirm that HCWs' presence at work during an influenza pandemic is associated with their perception of risks related to personal and work activities. We find that only $52 \%$ of HCWs would report for work in the third scenario of our survey. In less severe situations, presence at work is higher than $88 \%$. Further, we find that HCWs' opinion can change when the risk issue becomes more social, i.e., not only personal. Indeed, $45 \%$ of HCWs who did not intend to (and 57\% of those who did not know whether they would) RFW in the third scenario would change their intention in the event of a severe labor shortage.

We integrated more familiar risks, such as smoking, in the model, along with less familiar risks such as the impact of a potential H5N1 pandemic. HCWs who overestimate the personal and work risks they face regularly are less likely to be present at work during an influenza pandemic, whereas perception of a previously encountered risk (the impact of a potential H5N1 pandemic) is not significant in explaining presence at work. This difference has consequences on the planning of resource allocation because the misperception of risk of personal and work activities can be corrected with periodic information and education programs. Better knowledge of personal and work risks would improve resource allocation not only during a pandemic influenza, but also for many current risks at work and for future potential pandemic risks affecting HCWs.

Our research also identifies many organizational factors that affect HCWs' tendency to report for work during an influenza pandemic. These include sanitary measures at work, their role at work during an influenza pandemic, the importance of their role during an influenza pandemic, and transportation during a pandemic.

One limitation of our analysis is that the emotional dimension of risk perception is not considered. Some argue that public decisions must be based on experts' risk perception whereas others think that the public's perception is as valid as that of scientists, perhaps more so. Our sample represents HCWs who are not necessarily experts in risk management. Emotional risk perception implies that individual risk perception is a function of fear and anxiety, for example. Our questions on perceived risk in Table 3 are stated more explicitly in cognitive terms than in emotional terms. However, it should be noted that the subjects of our study are health professionals who may have less emotional and better documented judgment than lay people concerning personal and work risks. The difference may be less obvious for the questions related to reporting for work during an influenza pandemic because the HCWs had not experienced this risk before the survey period. Our methodology cannot distinguish the cognitive and affective domains among the reporting for work responses because our research was not designed for that purpose. This means that additional variables in the model that control for the affective domain might have improved the explanation of the decision to report for work. As an illustration, we control for fear of contracting an infectious disease in Table 6; this behavioral variable significantly explains the probability of being present at work. Those who did not change their behavior due to fear of infectious disease are more willing to report for work $(\mathrm{OR}=1.58 ; 95 \%)$. This indicates that this affective variable is complementary to the risk perception scores and organizational variables considered in explaining willingness to report for work. Further research must therefore treat the affective domain in risk perception regarding personal and work activities more explicitly so that better intervention tools can be developed.

Another potential caveat is that personal and work risks are individual risks, whereas pandemic risks are more social in the sense that externalities between individuals are involved and decisions to go to work can be influenced by normative behaviors. One interesting result of our research is that some important decisions are reversible when the social aspect of the pandemic becomes more important. Therefore, clear identification of private and social risks would also be a worthy focus of future research on the effect of risk perception on RFW. Our reversible results must therefore be interpreted prudently. The large effect of $45 \%$ may have been influenced by the phrasing of the 
question, and may contain a social desirability bias. The novelty of the result and its importance nonetheless warrants further investigation.

The findings of this study identify many causes for absence from work during an influenza pandemic. The four main barriers to willingness to report for work are: (1) I want to protect my personal health (50\%); (2) I want to protect my family's health (36\%); (3) I have to take care of my children or other dependents (5\%); and (4) I do not trust the safety measures at my work (4\%). Each barrier involves actions by different stakeholders in the planning of resource allocation during a pandemic. Vaccination, specific preventive measures, and personal protective equipment are often cited as among the first priorities when planning resources for a pandemic, but vaccines may not be available during the early phases of H5N1. HCWs may then be asked to RFW without this protection. In our survey, the availability of vaccines was not mentioned explicitly in questions about presence at work. Those who said "No" to the three scenarios indicated that the three following measures would be important to minimize the impacts of an influenza pandemic: (1) Reinforce workplace protection (56\%); (2) Provide access to preventive medication (29\%); and (3) Better define workers' role in such a situation $(7 \%)$. The vaccine is therefore not the sole and even the predominant measure to improve worker participation. This may explain why hygiene measures at work, the determination of each HCW's role and the importance of this role were found to be significant in the analysis of the results presented in Table 6. Our findings also suggest that national pandemic influenza preparedness programs must coordinate the transportation of HCWs with healthcare institutions' needs and schedules.

Improved risk perception is linked to education: our results suggest that the health care system must continuously provide better information on risks. Implementation of precautionary behavior at work based on accurate risk perception can supplement other organizational measures of risk prevention. Finally, knowing HCWs' perception of different risks is an important resource allocation instrument for unanticipated pandemics because risk perception seems to be a good predictor of RFW. Knowledge of risks associated with personal and work activities thus complements knowledge and perception of the influenza pandemic and other intervention policies.

Acknowledgments: We would like to thank the CIHR Pandemic Preparedness Research Program in Canada and the Canada Research Chair in Risk Management for their financial support. We also thank two referees for their constructive comments.

Author Contributions: Georges Dionne and André Dascal conceived and designed the experiments; Martin Lebeau and Stéphane Messier performed the experiments; Denise Desjardins analyzed the data; all authors contributed to reagents/materials/analysis tools; Georges Dionne wrote the paper.

Conflicts of Interest: The authors declare no conflicts of interest.

\section{References}

Abraham, Charles, and Paschal Sheeran. 2015. The Health Belief Model. In Predicting and Changing Health Behavior. Edited by Mark Conner and Paul Norman. New York: McGraw-Hill.

Althaus, Catherine E. 2005. A Disciplinary Perspective on the Epistemological Status of Risk. Risk Analysis 25: 567-88. [CrossRef] [PubMed]

Anderson, Henrik, and Petter Lundborg. 2007. Perception of Own Death Risks-An Analysis of Road-Traffic and Overall Mortality Risks. Journal of Risk and Uncertainty 34: 67-84.

Antoñanzas, Fernando, W. Kip Viscusi, Joan Rovira, Francisco J. Braña, Fabiola Portillo, and Irineu Carvalho. 2000a. Smoking Risks in Spain: Part I-Perception of Risks to the Smoker. Journal of Risk and Uncertainty 21: 161-86. [CrossRef]

Antoñanzas, Fernando, W. Kip Viscusi, Joan Rovira, Francisco J. Braña, Fabiola Portillo, and Irineu Carvalho. 2000b. Smoking Risks in Spain: Part III-Determinants of Smoking Behavior. Journal of Risk and Uncertainty 21: 212-34. [CrossRef]

Arrow, Kenneth J. 1982. Risk Perception in Psychology and Economics. Economic Inquiry 20: 1-9. [CrossRef]

Aven, Terje. 2012a. The Risk Concept-Historical and Recent Development Trends. Reliability Engineering and System Safety 99: 33-44. [CrossRef] 
Aven, Terje. 2012b. Foundations Issues in Risk Assessment and Risk Management. Risk Analysis 32: 1647-56. [CrossRef] [PubMed]

Aven, Terje, and V. Kristensen. 2005. Perspectives on Risk: Review and Discussion on the Basis for Establishing a Unified and Holistic Approach. Reliability Engineering and System Safety 90: 1-14. [CrossRef]

Balicer, Ran D., Saad B. Omer, Daniel J. Barnett, and George S. Everly Jr. 2006. Local Public Health Workers' Perceptions toward Responding to an Influenza Pandemic. BMC Public Health 6: 99. [CrossRef] [PubMed]

Brewer, Noel T., Gretchen B. Chapman, Frederick X. Gibbons, Meg Gerrard, and Kevin D. McCaul. 2007. Meta-Analysis of the Relationship between Risk Perception and Health Behavior: The Example of Vaccination. Health Psychology 26: 136-45. [CrossRef] [PubMed]

Brown, Stephen L., and Amy Cotton. 2003. Risk-mitigating, Risk Estimates, and Self-reported Speeding in a Sample of Australian Drivers. Journal of Safety Research 34: 183-88. [CrossRef]

Carman, Katherine Grace, and Peter Kooreman. 2014. Probability Perceptions and Preventive Health Care. Journal of Risk and Uncertainty 49: 43-71. [CrossRef]

Combs, Barbara, and Paul Slovic. 1979. Causes of Death: Biased Newspaper Coverage and Biased Judgements. Journalism Quarterly 56: 837-43. [CrossRef]

Dionne, Georges, Claude Fluet, and Denise Desjardins. 2007. Predicted Risk Perception and Risk-taking Behavior: The Case of Impaired Driving. Journal of Risk and Uncertainty 35: 237-64. [CrossRef]

Hakes, Jahn K., and W. Kip Viscusi. 1997. Mortality Risk Perceptions: A Bayesian Reassessment. Journal of Risk and Uncertainty 15: 135-50. [CrossRef] [PubMed]

Ives, Jonathan, Sheila Greenfield, Jayne M. Parry, Heather Draper, Christine Gratus, Judith I. Petts, Tom Sorell, and Sue Wilson. 2009. Healthcare Workers' Attitude to Working during Pandemic Influenza: A Qualitative Study. BMC Public Health 9: 56. [CrossRef] [PubMed]

Kim, Jae-On, and Charles W. Mueller. 1978. Introduction to Factor Analysis: What It Is and How To Do It. Newbury Park: Sage Publications.

Leoni, Thomas. 2010. What Drives the Perception of Health and Safety Risks in the Workplace? Evidence from European Labour Markets. Empirica 37: 165-96. [CrossRef]

Leppin, Anja, and Arja R. Aro. 2009. Risk Perception to SARS and Avian Influenza: Theoretical Foundations of Current Empirical Research. International Journal of Behavioral Medicine 16: 7-29. [CrossRef] [PubMed]

Liu, Jin-Tan, and Chee-Ruey Hsieh. 1995. Risk Perception and Smoking Behavior: Empirical Evidence from Taiwan. Journal of Risk and Uncertainty 11: 139-57. [CrossRef]

Lundborg, Petter. 2007. Smoking, Information Sources and Risk Perceptions-New Results on Swedish Data. Journal of Risk and Uncertainty 34: 217-40. [CrossRef]

Magat, Wesley A., W. Kip Viscusi, and Joel Huber. 1987. Risk-Dollar Tradeoffs. Risk Perceptions and Consumer Behavior. In Learning about Risk. Edited by W. Kip Viscusi and Wesley A. Magat. Cambridge: Harvard University Press.

O'Neil, Eoin, Finbarr Brereton, Harutyun Shahumyan, and J. Peter Clinch. 2016. The Impact of Perceived Flood Exposure on Flood-Risk Perception: The Role of Distance. Risk Analysis 36: 2158-86. [CrossRef] [PubMed]

Parker, Dianne, Antony S. Manstead, Stephen G. Stradling, James T. Reason, and James S. Baxter. 1992. Intentions to Commit Driving Violations: An Application of the Theory of Planned Behavior. Journal of Applied Psychology 77: 94-101. [CrossRef]

Phelps, Charles E. 1987. Risk and Perceived Risks of Drinking and Driving among Youths. Journal of Policy Analysis and Management 6: 708-13. [CrossRef]

Rubin, Donald B. 1987. Multiple Imputation for Nonresponse in Surveys. New York: Wiley \& Sons.

Ryb, Gabriel E., Patricia C. Dischinger, Joseph Kufera, and Kathy M. Read. 2006. Risk Perception and Impulsivity: Association with Risky Behaviors and Substance Abuse Disorders. Accident Analysis and Prevention 38: 567-73. [CrossRef] [PubMed]

Slovic, Paul, Baruch Fischhoff, and Sarah Lichtenstein. 1982. Facts versus Fears: Understanding Perceived Risk. In Judgement under Uncertainty: Heuristics and Biases. Edited by Daniel Kahneman, Amos Tversky and Paul Slovic. Basel: Cambridge Press, pp. 462-92.

Smith, V. Kerry, and F. Reed Johnson. 1988. How Do Risk Perceptions Respond to Information? The Case of Radon. The Review of Economics and Statistics 70: 1-8. [CrossRef]

Smith, V. Kerry, William H. Desvousges, F. Reed Johnson, and Ann Fisherc. 1990. Can Public Information Programs Affect Risk Perceptions? Journal of Policy Analysis and Management 9: 41-59. [CrossRef] 
Stasson, Mark, and Martin Fishbein. 1990. The Relation between Perceived Risk and Preventive Action: A Within-Subject Analysis of Perceived Driving Risk and Intentions to Wear Seabelts. Journal of Applied Social Psychology 20: 1541-57. [CrossRef]

Svenson, Ola, Baruch Fischhoff, and Donald MacGregor. 1985. Perceived Driving Safety and Seatbelt Usage. Accident Analysis and Prevention 17: 119-33. [CrossRef]

Viscusi, W. Kip. 1985. A Bayesian Perspective on Biases in Risk Perception. Economics Letters 17: 59-62. [CrossRef] Viscusi, W. Kip. 1990. Do Smokers Underestimate Risks? Journal of Political Economy 98: 1253-69. [CrossRef] Viscusi, W. Kip. 1992. Smoking: Making the Risky Decision. New York: Oxford University Press.

Viscusi, W. Kip, and Charles J. O'Connor. 1984. Adaptive Responses to Chemical Labelling: Are Workers Bayesian Decision Makers? American Economic Review 74: 942-56.

(C) 2018 by the authors. Licensee MDPI, Basel, Switzerland. This article is an open access article distributed under the terms and conditions of the Creative Commons Attribution (CC BY) license (http:/ / creativecommons.org/licenses/by/4.0/). 